\title{
Antimicrobial Susceptibility Result
}

National Cancer Institute

\section{Source}

National Cancer Institute. Antimicrobial Susceptibility Result. NCI Thesaurus. Code C85563.

A microbial susceptibility test result in which the growth of microorganisms is inhibited by the usually achievable concentrations of antimicrobial agent when the recommended dosage is used for the site of infection. 